\title{
Xeroderma Pigmentosum Group A Protein and Chemotherapy Resistance in Human Germ Cell Tumors
}

\author{
Friedemann Honecker, Frank Mayer, Hans Stoop, J. Wolter Oosterhuis, \\ Sandra Koch, Carsten Bokemeyer, and Leendert H. J. Looijenga
}

Department of Pathology (FH, FM, HS, JWO, LHJL), Laboratory for Experimental Patho-Oncology, Josephine Nefkens Institute, Erasmus MC, University Medical Center Rotterdam, Daniel den Hoed Cancer Center, Rotterdam, the Netherlands; and Department of Hematology-Oncology (FH, FM, SK, CB), University of Tübingen, Tübingen, Germany

SUMMARY: The exceptional sensitivity of germ cell tumors (GCTs) of adolescents and adults to chemotherapy, in particular to cisplatin, has been attributed to low levels of xeroderma pigmentosum group A protein (XPA), a crucial component of the nucleotide excision repair DNA repair pathway. In different types of solid tumors, resistance to cisplatin has been associated with enhanced expression of XPA. To assess the role of XPA levels in clinical sensitivity and resistance of GCTs to chemotherapy, immunohistochemistry was performed on tumor samples of both unselected patients before therapy and patients with fully documented clinical course before and after therapy. In the case of high XPA levels, fluorescent in situ hybridization was applied to assess the possibility of gene amplification. XPA protein levels were investigated by Western blot analysis after repeated exposure to cisplatin in different GCT-derived cell lines. Finally, XPA levels of both sensitive and cisplatin-resistant GCT cell lines were compared with cell lines derived from other neoplasms. We found that the presence of XPA protein as assessed by immunohistochemistry differs among the various histologies of GCTs. It is found more frequently and with a more homogenous staining pattern in histologic subtypes showing a more differentiated phenotype. Overall, no differences in the presence of XPA was observed between samples of tumors refractory or sensitive to chemotherapy. No XPA gene amplification was found. Interestingly, all tumors resected in relapse after chemotherapy in the refractory group stained positive for XPA. However, XPA was not induced by repeated courses of sublethal doses of cisplatin in GCT-derived cell lines in vitro, and no correlation between XPA protein levels and sensitivity to cisplatin in three GCT-derived cell lines was observed. We therefore conclude that XPA does not play a critical role in overall treatment resistance of GCTs. (Lab Invest 2003, 83:1489-1495).

$G$ erm cell tumors (GCTs) of the testis are the most frequent solid tumor in Caucasian men between 20 and 45 years of age (Adami et al, 1994). Histologically, they display patterns that resemble stages of embryonal development (Looijenga and Oosterhuis, 1999, 2002). Seminomas show characteristics of early germ cells (primordial germ cells or gonocytes), whereas nonseminomas can contain different, both embryonic and extra-embryonic, elements. The embryonal carcinoma is the stem cell component of nonseminomas, which may differentiate into yolk sac tumor, choriocarcinoma, and teratoma.

Seminomas and nonseminomas are highly sensitive to chemotherapy, notably to cisplatin (Einhorn, 2002).

DOI: 10.1097/01.LAB.0000090221.95883.41

Received May 22, 2003.

This work was supported by the Dutch Cancer Society (H.S., J.W.O., L.H.J.L.), Deutsche Krebshilfe, Dr. Mildred Scheel Stiftung (F.H.), and the European Society for Medical Oncology (F.M.).

Address reprint requests to: Dr. L.H.J. Looijenga, Department of Pathology, Laboratory for Experimental Patho-Oncology, Erasmus MC, University Medical Center Rotterdam, Josephine Nefkens Institute, Room 430b, P.O. Box 1738, 3000 DR Rotterdam, the Netherlands. E-mail: l.looijenga@erasmusmc.nl
Presently, more than $80 \%$ of patients with metastatic disease can be cured by cisplatin-based combination chemotherapy. However, mature teratomas are intrinsically resistant to chemotherapy. This histology is found in about $40 \%$ of residual lesions after chemotherapy and should be resected to prevent malignant transformation and development of secondary nongerm cell malignancies (Fizazi et al, 2001; Oosterhuis et al, 1983). The biological basis of the overall high sensitivity to chemotherapy and the infrequent but mostly lethal occurence of resistant phenotypes remains unclear.

Different mechanisms of cellular resistance to cisplatin have been described, including inhibition of drug uptake and increased efflux, inactivation by sulfur-containing proteins, enhanced replicative bypass of platinum DNA adducts, changes in concentrations of regulatory proteins, and enhanced repair of DNA crosslink lesions caused by cisplatin (Kartalou and Essigmann, 2001; Mayer et al, 2003; Reed, 1998). Nucleotide excision repair (NER) is believed to be the main mechanism by which damage caused by cisplatin through formation of bulky DNA adducts is repaired in mammalian cells (Chaney and Sancar, 1996; Zamble and Lippard, 1995). Xeroderma pigmentosum 
group A protein (XPA), involved in the NER system, is a zinc finger protein that is absent or aberrant in cells of patients with xeroderma pigmentosum complementation group A (Bootsma et al, 2001). Binding of XPA to the replication protein $A$ is the initiating and ratelimiting step of NER (Matsuda et al, 1995). It subsequently recruits other factors to damaged substrates (Buschta-Hedayat et al, 1999). GCT-derived cell lines were found to have low XPA levels and a low NER capacity. This finding was proposed as the major reason for the high sensitivity of GCTs to chemotherapy (Koberle et al, 1999). The XPA gene maps to chromosome 9q22, one of the regions found to be specifically amplified in GCTs showing chemotherapy resistance (Rao et al, 1998).

The objective of the present study is to investigate the presence of XPA in GCTs and clarify its role in sensitivity and resistance to cisplatin-based chemotherapy. XPA status was assessed by immunohistochemistry in tumor samples from patients with histologically defined GCTs without information on clinical outcome. To correlate immunohistochemical findings with clinical outcome, tumors from patients with fully documented clinical course, including chemotherapysensitive and refractory cases, were investigated. In addition, the correlation between XPA protein levels and cisplatin sensitivity was investigated by immunoblotting in different cell lines, including GCT cell lines with defined sensitivity and resistance to cisplatin.

\section{Results}

The presence of XPA protein was investigated in different histological elements of GCTs, including carcinoma in situ (CIS), their obligatory precursor lesion in the testis. Immunohistochemistry was performed on paraffin-embedded tissue sections of 85 unselected tumors of all histologic variants (Table 1). XPA showed a nuclear localization in the tumor cells with differing frequency and intensity in the different subtypes and

Table 1. Immunohistochemical detection of xeroderma pigmentosum group A protein in CIS and in GCTs of different histologies (unselected tumor samples) ${ }^{a}$

\begin{tabular}{|c|c|c|}
\hline Histology & $\begin{array}{c}\text { Cases } \\
\text { showing any } \\
\text { positivity, \% }\end{array}$ & $\begin{array}{l}\text { Cases with }>50 \% \\
\text { positive nuclei, } \%\end{array}$ \\
\hline $\mathrm{EC}(n=15)$ & 26 & 13 \\
\hline $\mathrm{SE}(n=33)$ & 48 & 24 \\
\hline $\operatorname{CC}(n=4)$ & 50 & 50 \\
\hline $\mathrm{YS}(n=18)$ & 61 & 44 \\
\hline $\begin{array}{l}\text { TE }(n=23, \text { including } 4 \\
\text { RMT) }\end{array}$ & 100 & 95 \\
\hline $\begin{array}{l}\text { CIS containing samples } \\
\quad(n=5)^{b}\end{array}$ & & \\
\hline
\end{tabular}

CC, choriocarcinoma; CIS, carcinoma in situ; EC, embryonal carcinoma; GCTs, germ cell tumors; RMT, residual mature teratoma; SE, seminoma; TE, teratoma; YS, yolk sac tumor.

${ }^{a}$ The majority of cases showed more than one histological subtype.

${ }^{b} 25 \%$ positivity of all CIS cells. histologic elements. Figure 1 shows representative examples, including normal spermatogenesis. Embryonal carcinomas showed staining in $26 \%$ of cases $(4$ of 15), followed by seminomas (16 of $33,48 \%$ ), choriocarcinoma (2 of $4,50 \%$ ), and yolk sac tumors (11 of 18, 61\%). Interestingly, all teratomas (19 primary cases and 4 residual mature teratomas) were strongly positive. The overall percentage of positive tumor cells varied between different subtypes and histologies. Seminomas and embryonal carcinomas displayed a heterogenous staining pattern with only a few tumors ( $n=8 / 33$ and $2 / 15$, respectively) showing more than $50 \%$ positivity. Yolk sac tumors, choriocarcinomas, and teratomas revealed a much more homogenous staining, with up to $100 \%$ of nuclei being positive. About $25 \%$ of the CIS cells, as present in adjacent testicular parenchyma of invasive seminomas or nonseminomas ( $n=5)$, showed a positive staining for XPA. This positivity was confirmed using a doublestaining for C-KIT and XPA (Fig. 1B).

To assess a possible correlation between the presence of XPA and clinical outcome, we investigated samples of GCTs from patients with chemotherapysensitive $(n=12)$ and refractory $(n=23)$ tumors. Clinical information is given in Table 2. The immunohistochemical results demonstrated no difference between the two groups: 9 of $12(75 \%)$ tumors in the chemosensitive and 16 of 23 (70\%) tumors in the refractory group stained positive for XPA (Table 2). However, all tumors sampled after chemotherapy $(n=$ 9) in the refractory group were positive for XPA. The histologies found in these cases were yolk sac tumor $(n=7)$, teratoma $(n=2)$, and choriocarcinoma $(n=2$; some of the tumors exhibited more than one histologic subtype). No gene amplification of XPA was found using double-color fluorescent in situ hybridization (FISH) on tumors showing strong XPA expression in the refractory group ( $n=9$ cases).

To investigate possible mechanisms related to the consistent presence of XPA in the refractory GCTs after cisplatin exposure, we investigated the total amount of XPA protein in three well-characterized GCT-derived cell lines (NT2, 2102Ep, and NCCIT) by Western blotting. Whereas NCCIT showed a low and 2102Ep an intermediate expression level, NT2 contained XPA at a level comparable to that of various other tumor cell lines (Fig. 2A). Furthermore, in cytotoxicity assays no correlation between XPA level and cisplatin sensitivity was observed (Fig. 2B). Continuous treatment with $0.5 \mu \mathrm{M}$ and $1.5 \mu \mathrm{M}$ cisplatin, respectively, for up to 48 hours did not result in up-regulation of XPA in NT2 or 2102Ep (Fig. 2C). Subsequently, NT2 and 2102Ep cells were repeatedly treated with sublethal doses of cisplatin, resulting (after 18 cycles of treatment) in cell lines relatively resistent to cisplatin. The NT2 subline (NT2/CDDP) showed a 2.2-fold and the 2101EP subline (2102EP/ CDDP) a 2-fold resistance to cisplatin at the IC50 (Fig. 2B). However, this was not accompanied by an increase in the level of XPA in these sublines (Fig. 2A). 

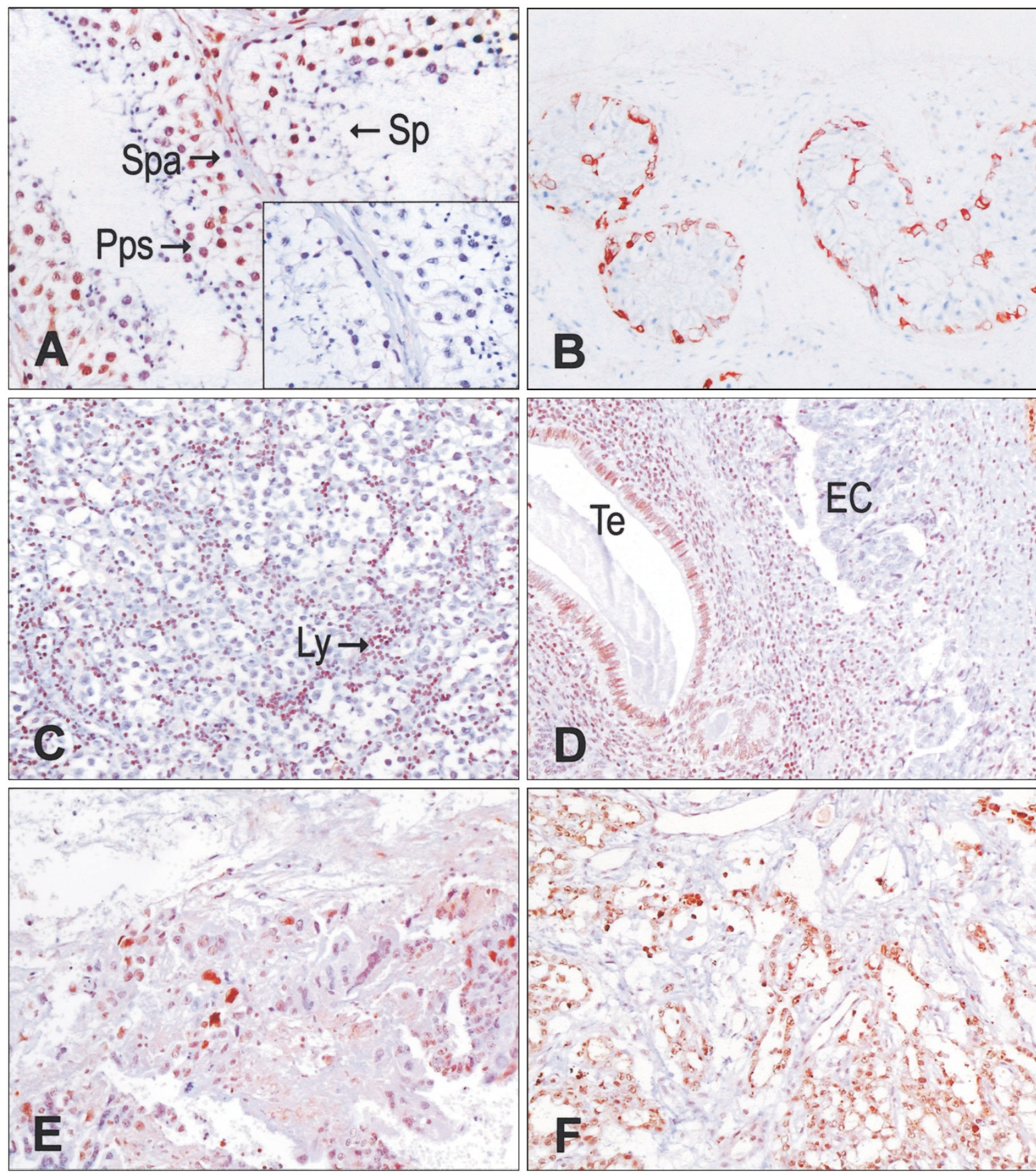

Figure 1.

Representative examples of the immunohistochemical stainings for xeroderma pigmentosum group A protein (XPA) in normal testis and germ cell tumors (GCTs) of different histologic subtypes. All sections have been lightly counterstained with hematoxylin with exception of B (double-staining), which was not counterstained to allow identification of both stainings. (A) Normal testicular parenchyma. Note positivity of germ cells at various stages of maturation as reported before (Stoop et al, 2001). Primary and pachytene spermatocytes (Pps) are XPA positive, whereas spermatogonia (Spa) and spermatids (Sp) are negative. Insert: Negative control (primary antibody omitted). (B) Seminiferous tubules containing carcinoma in situ (CIS) cells. Double-staining for c-KIT (red membrane-bound staining) and XPA (blue nuclear staining). All CIS cells show positivity for C-KIT and can be either positive or negative for XPA. (C) Seminoma, negative for XPA. Note positivity of infiltrating lymphocytes (Ly). (D) Nonseminoma containing both teratoma $(T e)$ showing epithelial differentiation positive for XPA and embryonal carcinoma (EC) negative for XPA. Note that stromal cells and infiltrating lymphocytes can be positive for XPA. (E) Choriocarcinoma showing a heterogeneous staining for XPA. Note the varied staining reaction of the multinucleated syncytiotrophoblasts. (F) Yolk sac tumor positive for XPA.

\section{Discussion}

The unique chemosensitivity of GCTs is poorly understood on a molecular level so far (Mayer et al, 2003). Based on studies on the mouse teratocarcinoma cell line P19, it has been assumed that a high level of wild-type p53 results in a low threshold for induction of apoptosis (Lutzker and Levine, 1996; Lutzker et al, 2001). However, this model differs from human GCTs in various parameters, and we recently demonstrated that treatment outcome in patients with GCTs does not correlate with p53 status (Kersemaekers et al, 
Table 2. Characteristics of patients with proven chemosensitive or refractory germ cell tumors

\begin{tabular}{|c|c|c|}
\hline & $\begin{array}{l}\text { Chemosensitive } \\
\quad(n=12)\end{array}$ & $\begin{array}{l}\text { Refractory } \\
(\mathrm{n}=22)\end{array}$ \\
\hline \multicolumn{3}{|l|}{ Age, years } \\
\hline Median & 28 & 29 \\
\hline Range & $20-47$ & $17-56$ \\
\hline \multicolumn{3}{|l|}{ Histology } \\
\hline Seminoma & 1 & 1 \\
\hline Nonseminoma & 11 & 21 \\
\hline \multicolumn{3}{|l|}{$\begin{array}{l}\text { Stage at diagnosis } \\
\text { (per UICC) }\end{array}$} \\
\hline I & 0 & 3 \\
\hline II & 0 & 7 \\
\hline III & 12 & 12 \\
\hline \multicolumn{3}{|l|}{$\begin{array}{l}\text { Initial treatment after } \\
\text { surgery }\end{array}$} \\
\hline Surveillance & 0 & 2 \\
\hline Chemotherapy & 12 & 20 \\
\hline \multicolumn{3}{|l|}{ Follow-up, months } \\
\hline Median & 49 & 39 \\
\hline Range & $12-67$ & $11-180$ \\
\hline \multicolumn{3}{|l|}{$\begin{array}{l}\text { Relapse-free survival, } \\
\text { months }\end{array}$} \\
\hline Median & NR & 7.1 \\
\hline Range & & $0-150$ \\
\hline \multicolumn{3}{|l|}{$\begin{array}{l}\text { Response to initial } \\
\text { treatment }\end{array}$} \\
\hline Complete remission & 8 & 5 \\
\hline $\begin{array}{l}\text { Partial remission, marker } \\
\text { negative }\end{array}$ & 4 & 8 \\
\hline $\begin{array}{l}\text { Partial remission, marker } \\
\text { positive }\end{array}$ & 0 & 3 \\
\hline Progressive disease & 0 & 3 \\
\hline Unknown & 0 & 3 \\
\hline \multicolumn{3}{|l|}{ No. of regimens in relapse } \\
\hline Median & 0 & 3 \\
\hline Range & 0 & $1-9$ \\
\hline $\begin{array}{l}\text { Cases showing XPA } \\
\text { positivity }\end{array}$ & $75 \%(9 / 12)$ & $70 \%(16 / 23)$ \\
\hline
\end{tabular}

NR, not reached; UICC, International Union Against Cancer; XPA, xeroderma pigmentosum group A protein.

2002). It has also been suggested that the unique treatment sensitivity of GCTs could be explained by a defective repair of cisplatin-induced DNA damage related to low XPA (Koberle et al, 1999). Several observations seem to support this model. For example, mammalian cells deficient in NER are more sensitive to cisplatin than corresponding wild-type cells (Dijt et al, 1988; Poll et al, 1984). Expression of a truncated XPA protein exerting a dominant-negative effect sensitizes human tumor cells to UV light and cisplatin (Rosenberg et al, 2001). Moreover, an enhanced XPA expression is associated with resistance to cisplatin treatment in human ovarian cancer (Dabholkar et al, 1994). However, studies correlating NER with clinical data result in conflicting data for different tumor entities. For example, expression of several NER factors in patients with chronic lymphocytic leu-
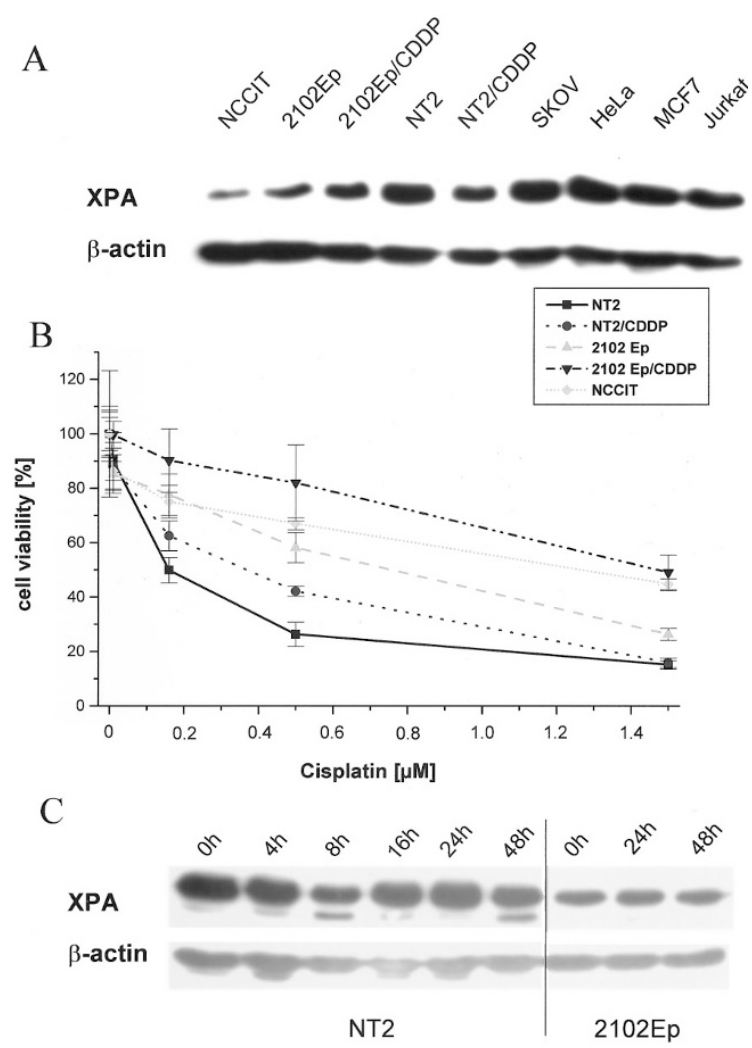

Figure 2.

(A) Immunoblot analysis for xeroderma pigmentosum group A protein (XPA) and $\beta$-actin on different cell lines derived from germ cell tumors (GCTs), including NT2/CDDP and 2102Ep/CDDP cell lines with acquired resistance to cisplatin following repeated sublethal exposure. SKOV, HeLa, MCF7, and Jurkat are cell lines derived from ovarian cancer, cervical cancer, breast cancer, and leukemia cells. (B) Cytotoxicity assay for selected GCT-cell lines. Note the lack of correlation between CDDP sensitivity and XPA level. (C) Immunoblot for XPA and $\beta$-actin on NT2 and 2102Ep cells during initial treatment with cisplatin (NT2: $0.5 \mu \mathrm{m}$ cisplatin, 2102Ep: $1.5 \mu \mathrm{m}$ cisplatin).

kemia did not correlate with resistance to nitrogen mustard (Bramson et al, 1995), while an increased NER capacity in patients with non-small-cell lung cancer may be associated with poorer survival (Bosken et al, 2002). It is of specific interest that a link between NER and differentiation has been observed in normal tissues; somatic stem cells are highly sensitive to the effects of physical and chemical mutagens (lijiri and Potten, 1987; Potten, 1977) and avoid certain forms of potentially error-prone DNA damage repair (Roth and Samson, 2002). It has been suggested that the choice of death rather than defective DNA repair in case of damage serves to avoid accumulation of replication errors with fatal consequences for the progeny (Cairns, 2002). So far, however, no data are available regarding NER and clinical outcome in GCTs.

The aim of this study is to assess the role of XPA in clinical resistance of GCTs. Immunohistochemistry in the unselected group of patients revealed that the staining pattern of XPA correlated with histology. In seminomas and in embryonal carcinoma, only a minority of cells contained detectable levels of XPA. In contrast, the majority of cells from choriocarcinomas, 
yolk sac tumors, or teratomas were positive for XPA. Three teratomas and yolk sac tumors of infants and neonates that were included in this series showed a similar staining pattern as the tumors in histologic counterparts found in testis of the adults (data not shown). No differences in the presence of XPA was evident comparing tumors of patients with cisplatinsensitive and refractory disease. The overall picture was heterogenous, as high expression of XPA was observed in several tumor samples of chemosensitive cases on the one hand, and lack of expression of XPA was seen in some refractory cases on the other hand. Results were in the same range as in the unselected group. Therefore, we conclude that XPA detection by immunohistochemistry has no prognostic or predictive value for patients with newly diagnosed GCTs.

None of the resistant tumors with detectable levels of XPA showed amplification of the respective locus using FISH analysis. This excludes amplification of the XPA gene as a common mechanism of chemotherapy resistance in GCTs. However, it is noteworthy that all tumors sampled at relapse in the refractory group, ie, after exposure to chemotherapy, were positive for XPA. This could simply be due to the particular histology (yolk sac tumors, choriocarcinoma, and teratoma) found in this limited series. Alternatively, induction of XPA or selection for XPA-positive cells could have occurred during treatment. To test this hypothesis, an in vitro model was used, which showed no correlation between XPA levels and sensitivity to cisplatin in the three GCT-derived cell lines investigated. We found a low level of XPA only in NCCIT, the cell line with the lowest sensitivity to cisplatin, whereas the levels of 2102Ep and NT2 were only slightly lower or comparable to that found in cell lines derived from other neoplasms. In addition, XPA expression was not induced in GCT cells that acquired cisplatin resistance by repeated exposure to the drug, differing from findings reported from ovarian cancer-derived cell lines (Hector et al, 2001). In this context it is of interest that even a low level of XPA expression in deficient cells is sufficient for total complementation of cellular sensitivity and DNA repair activity (Muotri et al, 2002). In accordance with this, it has been reported that sensitivity to 170 different compounds, including cisplatin, tested in a cytotoxicity assay did not correlate with XPA levels in 60 human tumor cell lines (Xu et al, 2002).

In conclusion, we demonstrated that the presence of XPA protein as assessed by immunohistochemistry differs between the various histologies of GCTs. XPA is found more frequently and with a more homogenous staining pattern in the histologic subtypes with a more differentiated phenotype. Overall, no differences in the presence of XPA were observed between samples of tumors refractory or sensitive to chemotherapy. Furthermore, we did not find a correlation between XPA protein levels and sensitivity to cisplatin in three GCT-derived cell lines. We therefore conclude that XPA does not play a critical role in overall treatment resistance of GCTs. Further research is needed to elucidate the mechanisms of chemotherapy sensitivity and resistance in these tumors.

\section{Materials and Methods}

\section{Patient Material}

Unselected Group: Formalin-fixed paraffinembedded tissue blocks were retrieved from the archive of the Laboratory for Experimental PathoOncology, Department of Pathology, Erasmus MC, Rotterdam. The material was collected between 1991 and 2001 in close collaboration with urologists and pathologists in the Southwest of the Netherlands. Eighty-one tumors were collected before therapy. In four cases residual mature teratomas were removed after chemotherapy. No data on the clinical course of the patients were available.

Chemosensitive Group: Formalin-fixed, paraffinembedded samples collected before therapy from 12 patients diagnosed between 1995 and 1998 were investigated. Only patients with a complete remission or a marker negative partial remission after high-dose chemotherapy and a relapse-free follow-up of more than 1 year were included. The series consisted of 11 nonseminomas and one seminoma.

Refractory Group: Twenty-three formalin-fixed paraffin-embedded samples from 22 patients with chemotherapy-refractory disease diagnosed between 1991 and 1998 were investigated. Patients were considered refractory when progression or relapse occurred despite adequate initial or salvage treatment, including high-dose chemotherapy in some cases. The material of 14 patients was obtained at initial diagnosis; in nine cases, the material was sampled after exposure to chemotherapy from metastatic lesions in relapse. In one case, material from both the primary tumor and a metastatic tumor at relapse was available. The series consisted of 22 nonseminomas and one seminoma. Table 2 summarizes the characteristics of the patients with refractory and chemosensitive tumors. All cases were reviewed and diagnosed by J.W.O. according to the World Health Organization classification, and the fully documented clinical course was available for these patients.

\section{Cell Lines and Culture Conditions}

The GCT-derived cell lines NT2 and NCCIT were purchased from the American Type Tissue Culture (Manassas, Virginia). 2102Ep was a kind gift from M. Pera. MCF-7 (breast cancer), SKOV-3 (ovarian cancer), and HeLa (cervical cancer) were gifts from $P$. Brossart. Jurkat (human $T$ cell leukemia) was a gift from T. Brümmendorf (University of Tübingen Medical Center). Cells were grown as monolayer and maintained at $37^{\circ} \mathrm{C}$ in a humidified cell culture incubator with $5 \%$ carbon dioxide. NT2 were cultured in DMEM/ glutamax supplemented with 10\% FCS (Gibco BRL, Paisly, United Kingdom), penicillin (Biochrom), and streptomycin (Biochrom). NCCIT and 2102Ep were cultured in DMEM/nut mix F12 supplemented with $10 \%$ FCS, pencillin, streptomycin, and glutamin. All 
other cell lines were kept in HEPES-buffered RPMI (Gibco).

\section{Immunohistochemistry}

Paraffin sections of 3- $\mu \mathrm{m}$ thickness were mounted on Starfrost slides (Knittel Gläser, Germany), dried at $50^{\circ} \mathrm{C}$ overnight, deparaffinized, and rehydrated. For antigen retrieval, pressure cooking at 1.0 bar in citrate buffer $0.01 \mathrm{~mol} / \mathrm{L} \mathrm{pH} 6.0$ was used. All antibodies were diluted in PBS with 1\% BSA (Sigma, Zwijndrecht, the Netherlands). The primary antibody anti-XPA (mouse mAb, Ab-1 Clone 12F5; NeoMarkers, Freemont, California) was used in a dilution 1:100, and incubation time was 60 minutes at room temperature. Biotinlabeled rabbit-antimouse immunoglobulins and an avidin-biotin-HRP complex (both DAKO A/S, Glostrup, Denmark) were subsequently applied for 30 minutes each. DAB (Fluka, Switzerland) was used as a chromogen, and slides were lightly counterstained with Mayer's hematoxylin stain. Double-staining for CIS cells was performed incubating slides sequentially with c-KIT (rabbit polyclonal antibody, C-19, Santa Cruz Biotechnology, California) after pretreatment in a dilution 1:300 overnight at $4^{\circ} \mathrm{C}$ and XPA as described above. XPA was visualized using avidin-biotin-alkaline phosphatase complex with Fast blue (Sigma) as chromogen. Detection of the c-KIT specific antibody was done using the peroxidase-anti-peroxidase method with 3-amino-9-ethyl-carbazole (AEC) (Sigma) as chromogen. For a negative control, the primary antibody was omitted; lymphocytes and normal spermatogenesis (pachytene spermatocytes) as present in the histological sections under investigation were used as positive control. Two investigators (F.H. and F.M. or H.S.) assessed samples independently. For evaluation of percentage of positive cells, 200 cells were scored in three randomly selected high-power fields. Only clearly nuclear staining of intact cells was considered positive.

\section{Western Blotting and Amplification Analysis for XPA Using FISH}

Protein harvest, Western blotting procedure, and FISH were performed as previously described (Kersemaekers et al, 2002). The XPA probe for FISH was derived from BAC clone RP11-414C23. A cut-off level of $\geq 10$ signals per nucleus was chosen to assess amplification of the gene locus. Only intact nuclei of a minimum of 20 cells were scored.

\section{Cisplatin Treatment and Toxicity, Resistance Assay, and Cytotoxicity Assay}

In vitro cytotoxicity was determined by the 3-(4,5dimethylthiazol-2-yl)-2,5-diphenyltetrazoliumbromide(MTT-)assay (MTT-assay), which was performed according to standard protocols. One-thousand cells/ well were seeded in 96-well plates 8-fold, left to attach overnight, and were exposed to cisplatin in increasing concentration continuously for further 72 hours. The cisplatin-containing medium was carefully removed, replaced by medium containing MTT (Sigma), and incubated for 4 hours at $37^{\circ} \mathrm{C}$. The tetrazolium salt was dissolved in DMSO, and the extinction was measured at $570 \mathrm{~nm}$ on a Bio-Rad ELISA-reader. The results are expressed relative to the extinction of the cells grown in the absence of cisplatin.

\section{Induction of Drug Resistance}

Cells were treated in increasing sublethal doses of cisplatin (ranging from $0.6 \mu \mathrm{M}$ to $2.0 \mu \mathrm{M}$ ) for 2 hours, transferred to normal medium, and grown for 2 weeks before re-exposure to cisplatin. Exposure at each dose level was repeated three times.

\section{Acknowledgements}

We thank the pathologists and urologists in the Southwestern part of the Netherlands for their cooperation in collecting the tumor samples. We thank Dr. G. Zafarana for helpful discussions. The first two authors of this paper (FH, FM) contributed equally to the work.

\section{References}

Adami HO, Bergstrom R, Mohner M, Zatonski W, Storm H, Ekbom A, Tretli S, Teppo L, Ziegler H, Rahu M, et al (1994). Testicular cancer in nine northern European countries. Int $J$ Cancer 59:33-38.

Bootsma D, Kraemer KH, Cleaver J, and Hoeijmakers JHJ (2001). Nucleotide excision repair syndromes: xeroderma pigmentosum, cockayne syndrome, and trichothiodystrophy. In: Scriver CR, Beaudet AL, Sly WS, and Valle D, editors, The metabolic and molecular basis of inherited disease. New York: McGraw-Hill, 677-703.

Bosken $\mathrm{CH}$, Wei Q, Amos Cl, and Spitz MR (2002). An analysis of DNA repair as a determinant of survival in patients with non-small-cell lung cancer. J Natl Cancer Inst 94:10911099.

Bramson J, McQuillan A, and Panasci LC (1995). DNA repair enzyme expression in chronic lymphocytic leukemia vis-a-vis nitrogen mustard drug resistance. Cancer Lett 90:139-148.

Buschta-Hedayat N, Buterin T, Hess MT, Missura M, and Naegeli H (1999). Recognition of nonhybridizing base pairs during nucleotide excision repair of DNA. Proc Natl Acad Sci USA 96:6090-6095.

Cairns J (2002). Somatic stem cells and the kinetics of mutagenesis and carcinogenesis. Proc Natl Acad Sci USA 99:10567-10570.

Chaney SG and Sancar A (1996). DNA repair: Enzymatic mechanisms and relevance to drug response. J Natl Cancer Inst 88:1346-1360.

Dabholkar M, Vionnet J, Bostick-Bruton F, Yu JJ, and Reed E (1994). Messenger RNA levels of XPAC and ERCC1 in ovarian cancer tissue correlate with response to platinumbased chemotherapy. J Clin Invest 94:703-708.

Dijt FJ, Fichtinger-Schepman AM, Berends F, and Reedijk J (1988). Formation and repair of cisplatin-induced adducts to DNA in cultured normal and repair-deficient human fibroblasts. Cancer Res 48:6058-6062. 
Einhorn L (2002). Curing metastatic testicular cancer. Proc Natl Acad Sci USA 99:4592-4595.

Fizazi K, Tjulandin S, Salvioni R, Germa-Lluch JR, Bouzy J, Ragan D, Bokemeyer C, Gerl A, Flechon A, de Bono JS, Stenning S, Horwich A, Pont J, Albers P, De Giorgi U, Bower M, Bulanov A, Pizzocaro G, Aparicio J, Nichols CR, Theodore C, Hartmann JT, Schmoll HJ, Kaye SB, Culine S, Droz JP, and Mahe C (2001). Viable malignant cells after primary chemotherapy for disseminated nonseminomatous germ cell tumors: Prognostic factors and role of postsurgery chemotherapy-results from an international study group. J Clin Oncol 19:2647-2657.

Hector S, Bolanowska-Higdon W, Zdanowicz J, Hitt S, and Pendyala $L$ (2001). In vitro studies on the mechanisms of oxaliplatin resistance. Cancer Chemother Pharmacol 48: 398-406.

ljiri K and Potten CS (1987). Further studies on the response of intestinal crypt cells of different hierarchical status to eighteen different cytotoxic agents. $\mathrm{Br} \mathrm{J}$ Cancer 55:113-123.

Kartalou M and Essigmann JM (2001). Mechanisms of resistance to cisplatin. Mutat Res 478:23-43.

Kersemaekers AM, Mayer F, Molier M, van Weeren PC, Oosterhuis JW, Bokemeyer C, and Looijenga LH (2002). Role of P53 and MDM2 in treatment response of human germ cell tumors. J Clin Oncol 20:1551-1561.

Koberle B, Masters JR, Hartley JA, and Wood RD (1999). Defective repair of cisplatin-induced DNA damage caused by reduced XPA protein in testicular germ cell tumours. Curr Biol 9:273-276.

Looijenga LH and Oosterhuis JW (1999). Pathogenesis of testicular germ cell tumours. Rev Reprod 4:90-100.

Looijenga LH and Oosterhuis JW (2002). Pathobiology of testicular germ cell tumors: Views and news. Anal Quant Cytol Histol 24:263-279.

Lutzker SG and Levine AJ (1996). A functionally inactive p53 protein in teratocarcinoma cells is activated by either DNA damage or cellular differentiation. Nat Med 2:804-810.

Lutzker SG, Mathew R, and Taller DR (2001). A p53 doseresponse relationship for sensitivity to DNA damage in isogenic teratocarcinoma cells. Oncogene 20:2982-2986.

Matsuda T, Saijo M, Kuraoka I, Kobayashi T, Nakatsu Y, Nagai A, Enjoji T, Masutani C, Sugasawa K, Hanaoka F, et al (1995). DNA repair protein XPA binds replication protein A (RPA). J Biol Chem 270:4152-4157.

Mayer F, Honecker F, Looijenga LHJ, and Bokemeyer C (2003). Towards an understanding of the biological basis of the response to cisplatin-based chemotherapy in germ-cell tumors. Ann Oncol 14:825-832.
Muotri AR, Marchetto MC, Suzuki MF, Okazaki K, Lotfi CF, Brumatti G, Amarante-Mendes GP, and Menck CF (2002). Low amounts of the DNA repair XPA protein are sufficient to recover UV-resistance. Carcinogenesis 23:1039-1046.

Oosterhuis JW, Suurmeyer AJ, Sleyfer DT, Koops HS, Oldhoff $\mathrm{J}$, and Fleuren $\mathrm{G}$ (1983). Effects of multiple-drug chemotherapy (cis-diammine-dichloroplatinum, bleomycin, and vinblastine) on the maturation of retroperitoneal lymph node metastases of nonseminomatous germ cell tumors of the testis. No evidence for De Novo induction of differentiation. Cancer 51:408-416.

Poll EH, Abrahams PJ, Arwert F, and Eriksson AW (1984). Host-cell reactivation of cis-diamminedichloroplatinum(II)treated SV40 DNA in normal human, Fanconi anaemia and xeroderma pigmentosum fibroblasts. Mutat Res 132:181187.

Potten CS (1977). Extreme sensitivity of some intestinal crypt cells to $X$ and gamma irradiation. Nature 269:518-521.

Rao PH, Houldsworth J, Palanisamy N, Murty VV, Reuter VE, Motzer RJ, BosI GJ, and Chaganti RS (1998). Chromosomal amplification is associated with cisplatin resistance of human male germ cell tumors. Cancer Res 58:4260-4263.

Reed E (1998). Platinum-DNA adduct, nucleotide excision repair and platinum based anti-cancer chemotherapy. Cancer Treat Rev 24:331-344.

Rosenberg E, Taher MM, Kuemmerle NB, Farnsworth J, and Valerie K (2001). A truncated human xeroderma pigmentosum complementation group A protein expressed from an adenovirus sensitizes human tumor cells to ultraviolet light and cisplatin. Cancer Res 61:764-770.

Roth RB and Samson LD (2002). 3-Methyladenine DNA glycosylase-deficient Aag null mice display unexpected bone marrow alkylation resistance. Cancer Res 62:656-660.

Stoop H, van Gurp RJ, de Krijger R, van Kessel AG, Koberele B, Oosterhuis JW, and Looijenga LH (2001). Reactivity of germ cell maturation stage-specific markers in spermatocytic seminoma: Diagnostic and etiological implications. Lab Invest $81: 919-928$.

Xu Z, Chen ZP, Malapetsa A, Alaoui-Jamali M, Bergeron J, Monks A, Myers TG, Mohr G, Sausville EA, Scudiero DA, Aloyz R, and Panasci LC (2002). DNA repair protein levels vis-a-vis anticancer drug resistance in the human tumor cell lines of the National Cancer Institute drug screening program. Anticancer Drugs 13:511-519.

Zamble DB and Lippard SJ (1995). Cisplatin and DNA repair in cancer chemotherapy. Trends Biochem Sci 20:435-439. 